\title{
Intention to use long acting contraceptive methods and associated factors among women currently using short acting contraceptive methods in Gondar city, northwest Ethiopia: using the theory of planned behavior.
}

Resom Berhe ( $\sim$ resom.berhe86@gmail.com )

University of Gondar

Adane Nigusie

University of Gondar

Research note

Keywords: Intention, long acting contraceptive methods, theory of planned behavior

Posted Date: May 3rd, 2020

DOI: https://doi.org/10.21203/rs.3.rs-23589/v1

License: (c) (i) This work is licensed under a Creative Commons Attribution 4.0 International License.

Read Full License 


\section{Abstract}

Objective Despite its effectiveness, the intention and utilization of long acting contraceptive methods is very low in many developing countries and the use of long acting contraceptive methods has not kept in pace with that of short-acting methods such as, oral contraceptives and injectables.

Result The magnitude of intention to use long acting contraceptive methods was $39.8 \%$. Intention to use long acting contraceptive methods was higher for women whose husbands were farmers when compared to women whose husbands were government employees ( $\beta=0.49,95 \% \mathrm{Cl}: 0.41,0.72)$. Number of children wanted ( $\beta=-0.19,95 \% \mathrm{Cl}:-0.28,-0.1)$, attitude $(\beta=0.34, \mathrm{Cl}: 0.23,0.46)$, subjective norm $(\beta=19$, $95 \% \mathrm{Cl}: 0.12,0.27)$ and perceived behavioral control $(\beta=0.18,95 \% \mathrm{Cl}: 0.06,0.3)$ were factors significantly associated with intention to use long acting contraceptive methods. Intention to use long acting contraceptive methods was low. Interventions that focus on women's attitude towards long acting contraceptive methods and support group, peer education, social mobilization and persuasive communication could promote intention to use long acting contraceptive methods.

\section{Introduction}

Family planning can prevent at least 25 percent of all maternal deaths by allowing women to delay motherhood, prevent unintended pregnancies, and avoid unsafe abortions. It also protects women from sexually transmitted infections, including HIV/AIDS[1].

In many sub-Saharan African countries, long acting contraceptive methods practice have lowest rates and is sometimes missing component of national family planning programs [2]. For example, in Kenya, the contraceptive prevalence rate (CPR) increased from 17\% in 1984 to $19 \%$ in 2003. Despite its increase, a decreasing proportion (from 31-2\%) of Intra Uterine Device (IUD) use in the national method mix had been documented. Also in Guatemala even if contraceptive prevalence rate increased, decreasing proportion of IUD use in the method mix had been reported [3].

In Ethiopia, the contraceptive prevalence rate at national level has quadrupled from $6 \%$ in 2000 to $27 \%$ in 2011. But as most sub- Saharan African countries like Malawi and Rwanda, diversifying the method mix is still a big challenge. Injectables predominate, accounting for $76 \%$ of modern method use [4], where as long acting contraceptive methods (LACMs) contribute only $4.2 \%$. Implant $3.4 \%$, intrauterine device (IUD) $0.3 \%$. Unmet need for family planning is $25 \%$ and $22 \%$ for Ethiopia and Amhara Regional State, respectively [1].

Over long term, LARC methods are 20 times more effective than short term contraceptives [5].If only one of five sub-Saharan African women now using pills or injectables were to switch to an implant, more than 1.8 million unintended pregnancies would be averted in 5 years, resulting in almost 600,000 fewer abortions and 10,000 fewer maternal deaths[6]. 
Currently, the Ministry of Health $(\mathrm{MoH})$ has been giving due attention for expansion of LACMs. To achieve this goal, MoH has practiced the task shift, which enabled the Health Extension Workers to provide Implant at community level and the scale-up of Intrauterine Contraceptive Devices was initiated in more than 100 district hospitals and permanent contraceptive method at selected health centers and hospitals [7]. However, the contraceptive prevalence rate is still highly dependent on short-term family planning methods with low utilization of LACMs and unmet need for family planning is still high for spacing births (16\%) and limiting (9\%) [1].

Since intention is the best predictor of behavior (utilization of LACMs), this study assessed the intention to use long acting contraceptive methods and identify factors affecting it among short acting contraceptive users using the theory of planned behavior. Results from this study will help in developing evidence based LACMS health promotion programs.

\section{Methods}

\section{Study design and period}

Institution based cross sectional study was conducted from March to April, 2017.

\section{Sample size and Sampling procedure}

Sample size was determined by single population proportion formula using EPI INFO stat calc program with the assumption of population size $154,767,95 \%$ level of confidence, $4 \%$ of marginal error, and taking proportion of intention to use long acting contraceptives, Implants $71.3 \%$, IUCD 24.0\% [23]. Considering 5 $\%$ non-response rate, the final sample size became 519 . The study participants were selected by using systematic random sampling technique and the sampling interval was 2 .

\section{Data collection instruments and procedures}

Data were collected using a pre-tested, structured questionnaire having two parts. In the first section information about socio-demographic, economic and reproductive history was collected. In the second section, the theoretical constructs were measured. The number of questions for each construct varied between three and ten. Forty-four items of Theory of Planned Behavior (TPB) constructs were assessed on a 5- point Likert scale and they were scored into respective constructs for analysis. Since most women are not familiar with the phrase, long acting contraceptive methods, it was defined in the questioner as long acting contraceptive methods are methods that are used for three and above three years, IUCD and implant. The questionnaire was initially prepared in English and translated in to Amharic (the official language fluently spoken by all participants) and again translated back to English to check for any inconsistencies or distortions in the meaning of words and concepts. The reliability of the tool was checked using Cronbach's alpha reliability test with a score of 0.82 (95\% $\mathrm{Cl} 0.801-0.837)$.

\section{Operational definitions:}


Intention: Intent to use IUCD or implant within one year.

Attitude: The women's overall evaluation of the benefits and risk of long acting contraceptives.

Subjective norm: Women own assessment of the social pressure to use or not to use long acting contraceptive and her motivation to comply.

Short term contraceptives: Pills and depo provera injection that are taken on a daily basis and every three months.

\section{Results}

Demographic, socioeconomic characteristics information of the Participants

A total of 519 women of short-acting contraceptive users participated in this study with $99.2 \%$ response rate. The respondents' age ranged from 15 - 48 years with the mean age of 26.77 (SD \pm 6.1 ) years. One hundred sixty-two (31.5\%) participants were in the age category of 25 - 29. From the study participants $453(88 \%)$ were married. Majority of the women 468 (90.9\%) were Orthodox Christians and 478 (92.8\%) women were Amhara by ethnicity.

Concerning educational status, 167 (32.4\%) of the respondents were unable to read and write at all and $124(27.4 \%)$ of their husbands were unable to read and write. Regarding occupation of the respondents $250(48.5 \%)$ were housewives. The median monthly income of the respondents was \$74 (Table 1).

Table 1: socio demographic and economic characteristics of short acting contraceptive user women in Gondar city, Northwest Ethiopia, April 2017. 


\begin{tabular}{|c|c|c|c|}
\hline \multirow[t]{5}{*}{ Age category } & 15-19 & 83 & 16.1 \\
\hline & $20-24$ & 113 & 21.9 \\
\hline & $25-29$ & 162 & 31.5 \\
\hline & $30-34$ & 110 & 21.4 \\
\hline & $35-49$ & 47 & 9.1 \\
\hline \multirow[t]{2}{*}{ Marital status } & Married & 453 & 88.0 \\
\hline & Single & 62 & 12.0 \\
\hline \multirow[t]{3}{*}{ Religion } & Orthodox & 468 & 90.9 \\
\hline & Muslim & 35 & 6.8 \\
\hline & Protestant & 12 & 2.3 \\
\hline \multirow[t]{3}{*}{ Ethnicity } & Amhara & 478 & 92.8 \\
\hline & Tigray & 19 & 3.7 \\
\hline & Others & 18 & 3.5 \\
\hline \multirow[t]{2}{*}{ Residence } & Rural & 122 & 23.7 \\
\hline & Urban & 393 & 76.3 \\
\hline \multirow[t]{5}{*}{ Education } & can't read and write & 167 & 32.4 \\
\hline & 1-4th grade & 45 & 8.7 \\
\hline & 5- 8th grade & 95 & 18.4 \\
\hline & 9 - 12th grade & 135 & 26.2 \\
\hline & $12+$ & 73 & 14.2 \\
\hline \multirow[t]{7}{*}{ Occupation } & House wife & 250 & 48.5 \\
\hline & Government employee & 41 & 8.0 \\
\hline & Self employed & 96 & 18.6 \\
\hline & Daily laborer & 52 & 10.1 \\
\hline & Farmer & 14 & 2.7 \\
\hline & Student & 59 & 11.5 \\
\hline & Other & 3 & .6 \\
\hline
\end{tabular}




\begin{tabular}{|c|c|c|c|}
\hline \multirow[t]{6}{*}{ Husband's education } & can't read and write & 124 & 27.4 \\
\hline & 1-4th grade & 41 & 9.1 \\
\hline & 5- 8th grade & 72 & 15.9 \\
\hline & 9 - 12th grade & 82 & 18.1 \\
\hline & $12+$ & 134 & 29.6 \\
\hline & Total & 453 & 100 \\
\hline \multirow[t]{7}{*}{ Husband's Occupation } & Government employee & 93 & 20.5 \\
\hline & Self employed & 168 & 37.1 \\
\hline & Daily laborer & 73 & 16.1 \\
\hline & Farmer & 99 & 21.9 \\
\hline & Student & 19 & 4.2 \\
\hline & Other & 1 & 0.2 \\
\hline & Total & 453 & 100 \\
\hline \multirow[t]{6}{*}{ Income Category } & $<750$ Birr & 49 & 9.5 \\
\hline & $750-1500$ & 105 & 20.4 \\
\hline & $1500-2250$ & 137 & 26.6 \\
\hline & $2250-3000$ & 100 & 22.3 \\
\hline & $>3000$ & 58 & 11.3 \\
\hline & I don't know & 66 & \\
\hline
\end{tabular}

\section{Intention to use long acting contraceptive methods}

Intention to use LACMs was $39.8 \%$. One hundred sixty-five (32.1\%) of the women agreed they would make an effort to use LACMs and $12.2 \%$ were not sure if they would make an effort to use LACMs. 
Attitude wise, about $213(41.4 \%)$ participants believed that using LACMs is unpleasant. About 174 (33.8\%) of the participants opposed that using LACMs would help them work effectively. Nearly $181(39.7 \%)$ of the participants replied that using LACMs wouldn't not help them to have satisfying relationship with their husbands. About $213(41.4 \%)$ of the women agreed using LACMs would subject them to different problems.

With regard to subjective norm, about $214(41.6 \%)$ of the women answered that most people who are important to them think that they should not use LACMs. Two hundred twenty-three (43.3\%) of the respondents disagreed that most people whose opinions they valued would approve of their using LACMs.

Concerning perceived behavioral control, about $262(50.9 \%)$ of the respondents replied that it is difficult for them to use LACMs and $132(29.7 \%)$ of them answered that it is easy for them to use it. Two hundred ninety-four $(57.1 \%)$ of the women were confident that if they wanted to, they could use LACMs within one year. Nearly $360(69.9 \%)$ of the women answered that it is possible to use LACMs (Table 2).

Table 2. Intention to use long acting contraceptive methods among short acting contraceptive user women in Gondar city, northwest Ethiopia, March 19 to April 19, 2017. 


\section{Subjective Norm}

Most people who are important to me think that I should use LACMs

\begin{tabular}{lll} 
Very Unlikely & 113 & 21.9 \\
\hline Unlikely & 214 & 41.6 \\
\hline Uncertain & 97 & 18.8 \\
\hline Likely & 80 & 15.5 \\
\hline Very likely & 11 & 2.1
\end{tabular}

\section{Attitude towards LACM}

To use LACMs is

\begin{tabular}{lll} 
Very Harmful & 26 & 5.0 \\
\hline Harmful & 195 & 37.9 \\
\hline Not sure & 103 & 20.0 \\
\hline Beneficiary & 176 & 34.2 \\
\hline Very Beneficiary & 15 & 2.9 \\
\hline $\begin{array}{l}\text { Extremely } \\
\text { worthless }\end{array}$ & 5 & 1.0 \\
\hline Worthless & 73 & 14.2 \\
\hline Not sure & 85 & 16.5 \\
\hline Valuable & 331 & 64.3 \\
\hline Extremely valuable & 21 & 4.1 \\
\hline Extremely & 46 & 8.9 \\
\hline unpleasant & & \\
\hline Unpleasant & 213 & 41.4 \\
\hline Not sure & 144 & 28.0 \\
\hline Pleasant & 104 & 20.2 \\
\hline Extremely pleasant & 8 & 1.6 \\
\hline
\end{tabular}

To use LACMs is

To use LACMs is

\section{Perceived Behavioral Control}

For me to use LACMs is

\begin{tabular}{lll} 
Extremely difficult & 40 & 7.8 \\
\hline Difficult & 262 & 50.9
\end{tabular}




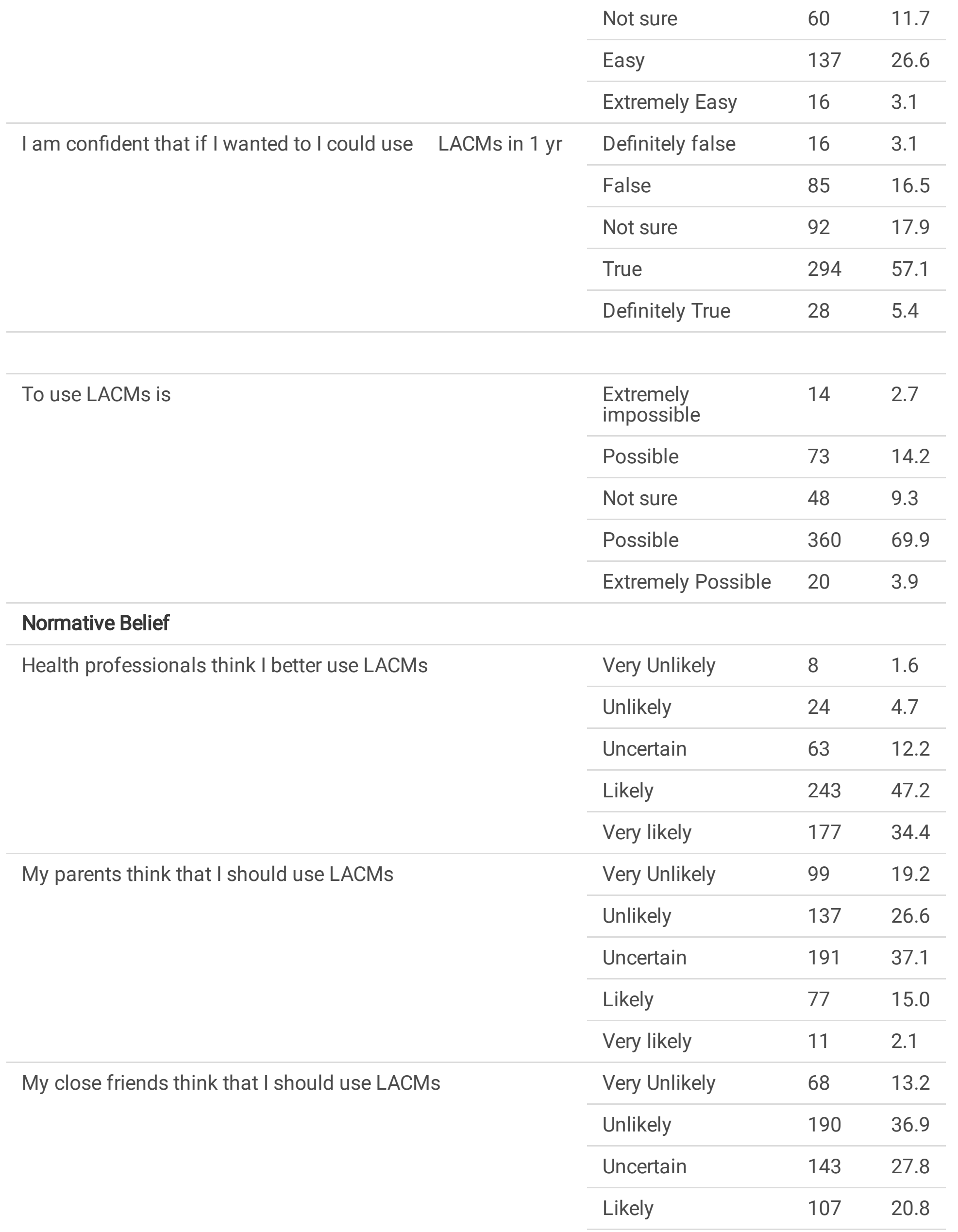




\begin{tabular}{llll} 
& Very likely & 7 & 1.4 \\
\hline My relatives think I should use LACMs & Very Unlikely & 60 & 11.7 \\
\cline { 2 - 4 } & Unlikely & 171 & 33.2 \\
\cline { 2 - 4 } & Uncertain & 209 & 40.6 \\
\cline { 2 - 4 } & Likely & 70 & 13.6 \\
\cline { 2 - 4 } & Very likely & 5 & 1.0 \\
\hline My husband thinks I should use LACMs & Very Unlikely & 138 & 30.3 \\
\cline { 2 - 4 } & Unlikely & 165 & 36.2 \\
\cline { 2 - 4 } & Uncertain & 54 & 11.8 \\
\cline { 2 - 4 } & Likely & 76 & 16.7 \\
\cline { 2 - 4 } & Very likely & 23 & 5.0
\end{tabular}

Factors affecting intention to use long acting contraceptive methods

The score on intention to use LACMs increased by 0.34 for every unit increase in score of attitudes ( $\beta=$ 0.34 , Cl: $0.23,0.46)$. For every unit increase in the score of subjective norms, the score of intention to use LACMs increased by $0.19(\beta=19,95 \% \mathrm{Cl}: 0.12,0.27)$. For every unit increase in the score of perceived behavioral control the score of intention to use LACMs increased by $0.18(\beta=0.18,95 \% \mathrm{Cl}$ : $0.06,0.3)$.

For women whose husbands were farmers, the score of intention to use LACMs increased by 0.43 when compared to women whose husbands were government employees ( $\beta=0.49,95 \% \mathrm{Cl}$ : $0.41,0.72)$. For every unit increase in number of children wanted in the future, the score of intention to use LACMs decreased by 0.19 ( $\beta=-0.19,95 \% \mathrm{Cl}:-0.28,-0.1)$ (Table 3).

Table 3: Factors associated with intention to use LACMs among short acting contraceptive user women in Gondar city, North West Ethiopia, March 19 to April 19, 2017. 


\begin{tabular}{|c|c|c|c|}
\hline Variables & $\boldsymbol{\beta}$ & & $95 \% \mathrm{Cl}$ \\
\hline Constant & & -2.31 & $(-3.03,-1.6)$ \\
\hline \multicolumn{4}{|l|}{ Occupation } \\
\hline House wife & \multicolumn{3}{|c|}{0} \\
\hline Government employee & -.061 & & $(-0.42,0.30)$ \\
\hline Self-employed & .109 & & $(-0.15,0.37)$ \\
\hline Laborers & -.033 & & $(-0.37,0.30)$ \\
\hline Farmers & -.255 & & $(-0.74,0.23)$ \\
\hline Student & .477 & & $(-0.04,0.99)$ \\
\hline Others & -.050 & & $(-1.2,1.11)$ \\
\hline \multicolumn{4}{|l|}{ Husband occupation } \\
\hline Government employee & 0 & & \\
\hline Self-employed & .102 & & $(-0.15,0.35)$ \\
\hline Laborer & .098 & & $(-0.22,0.41)$ \\
\hline Farmer & $.430 * *$ & & $(0.14,0.72)$ \\
\hline Student & -.042 & & $(-1.0,0.93)$ \\
\hline No of children wanted & & $-.186 *$ & $(-0.28,-0.1)$ \\
\hline Attitude & & $.343^{*}$ & $(0.23,0.46)$ \\
\hline Subjective norm & $.194^{\star}$ & & $(0.12,0.27)$ \\
\hline Perceived behavioral control & $.183^{* *}$ & & $(0.06,0.30)$ \\
\hline
\end{tabular}

** $p$ value $<0.005,{ }^{*} p$ value $<0.0001, R^{2}=40.1 \%$

$0=$ reference category

\section{Discussion}

The overall magnitude of intention to use LACMs within one year was $39.8 \%(95 \% \mathrm{Cl}$ : $35.7,44.3)$. This result was in line with the study done in Wolaita which was 38\%[20]. But it was slightly lower than the study done in Adigrat which was $48.6 \%[8]$. The difference could be due to disparities in the study settings and myths and misconceptions on long acting contraceptive methods. 
In this study attitude, subjective norm, and PBC were statistically significant factors of intention to use long acting contraceptive methods. These results support Ajzen's theoretical assumptions[23]. The more women have positive attitude, believe that people around them would approve of their actions and believe that they have a high degree of control over using IUCD and implant, the greater will be their intention to use LACMS.

Attitude plays the most important role in predicting women's intention to use LACMs. For each unit increase in score of attitudes, score of intention to use LACMs increased by 0.34 . Also the study in Wolaita, Ethiopia documented that those women who had positive attitude had higher intention to use LACMs than women who had negative attitude[20]. Most of the women thought using these methods would subject them to different problem and they thought it wouldn't allow them to effectively carryout their daily activities hence in fear of the perceived side effects they didn't intend to use LACMs.

Subjective norm ( $B=0.19,95 \% \mathrm{Cl}: 0.12,0.27)$ denotes that women felt significantly the social pressure from others. According to the interviews there was high pressure exerted mainly by spouses, relatives, and friends which didn't favor intention to use long acting contraceptive methods. Even if $81.1 \%$ of the respondents perceived health professionals want them to use LACMs, they didn't think relatives (44.9\%), husbands $(66.5 \%)$ and close friends $(50.1 \%)$ would want them to use LACMs. This might be the reason why regardless of health professionals' effort women failed to intend to use LACMs.

A unit increase in score of perceived behavioral control decreased the score of intention by 0.18 . Three hundred twenty-two (62.5\%) of the respondents agreed that if they wanted to use, they could use LACMs. This means that if they wanted to use LACMs, there was no barrier that could stop them from using LACMs. But 302(58.7\%) of the women agreed using LACMs was difficult for them. This might be due to fear of pain during insertion of implant or IUCD.

Number of children wanted was also significant $(\beta=-0.19,95 \% \mathrm{Cl}:-0.28,-0.1)$. As number of children wanted increase by a unit, the score of intention to use LACMs decreased by 0.19 . This finding was supported by the study done in Adigrat[8]. If they had a plan to conceive soon, they preferred short acting contraceptive methods. It might also be due to fear of side effects and the misconceptions that LACMs could harm the womb and cause infertility after the use of LACMs.

\section{Conclusion}

Intention to use LACMs was low. Attitude, subjective norm, perceived behavioral control, number of children wanted in the future, and husbands' occupations were factors significantly associated with intention to use LACMs. Therefore, Programs aimed at increasing LACMs utilization need to address these identified factors of LACMS against users of short acting contraceptive methods.

\section{Limitation Of The Study}


Social desirability bias was the limitation of the study because respondents perceived intending to use LACMs is expected of them. Therefore, there is some potential for reporting bias which may have occurred because of the respondents' interpretation of the questions or desire to report their emotions in a certain way or simply because of inaccuracies of responses.

\section{Abbreviations}

\begin{tabular}{ll} 
BI & Behavioral Intention \\
\hline CPR & Contraceptive Prevalence Rate \\
\hline EDHS & Ethiopian Demographic Health Survey \\
\hline FP & Family Planning \\
\hline HC & Health Center \\
\hline IUD & Intra Uterine Device \\
\hline LAPMs & Long Acting and Permanent Contraceptive Methods \\
LACMs & Long Acting Contraceptive Methods \\
\hline MoH & Ministry of Health \\
PBC & Perceived Behavioral Control \\
\hline RH & Reproductive Health \\
\hline SPSS & Statistical Package for Social Sciences \\
\hline SSA & Sub- Saharan Africa \\
\hline TPB & Theory of Planned Behavior \\
\hline WHO & World Health Organization
\end{tabular}

\section{Declarations}

\section{Ethical Approval and consent to participate}

Ethical clearance was obtained from Ethical review committee of Institute of public health, University of Gondar. All methods were performed in accordance with the relevant guidelines and regulations. Permission to conduct the research was obtained from Gondar city administration. Written Informed consent was obtained from respondents who were selected to participate in the study after explaining the purpose of the study and consent was obtained from the parents of minor study participants ( 15 years old). 


\section{Consent for Publication}

Not applicable

\section{Availability of data and material}

All data and material related to this article will be made available upon request

\section{Competing Interests}

The authors have declared that no competing interests exist.

\section{Funding}

Not applicable

\section{Author contributions}

RB conceived and designed the idea, analyzed the data. RB and AN wrote and critically reviewed the manuscript. All authors read and approved the final draft of manuscript.

\section{Acknowledgments}

The authors would like to acknowledge university of Gondar, Institute of public health for reviewing the ethics. The authors would also like to thank facilitators and the study participants for their dedicated cooperation and made the study possible.

\section{Author details}

${ }^{1}$ Department of Health Education and Behavioral sciences, College of Medicine and Health Sciences, University of Gondar, P.O. Box 196, Gondar, Ethiopia.

\section{Endnotes}

a Keble is the smallest administrative unit of the Federal Democratic Republic of Ethiopia.

\section{References}

1. Ethiopia Demographic and Health Survey Key Findings. In.; 2011.

2. USAID: long acting and permanent contraceptive methods:forum for putting knowledge into practice. 2008. 
3. Townsenda JW, Jacobstein R: the changing positions of IUDs in reproductive health services in developing countries: opportunities and challenges. elsevier 2007.

4. Jacobstein R, b CC, b JS, Radloff S: Meeting the need for modern contraception: Effective solutions to a pressing global challenge. International Journal of Gynecology and Obstetrics 2013.

5. long acting reversible contrceptation(LARC):IUD and implant. the american college of obstrician and gynecologyists 2014:1-4.

6. Jacobstein R, stanley h: contraceptive implant:providing better choice to meet growing family planning demand. global health: science and prctice:5-7.

7. national guidline for family plannning service in ehtiopia. In.: ministry of health; 2011.

8. Gebremariam A, Addissie A: Intention to use long acting and permanent contraceptive methods and factors affecting it among married women in Adigrat town, Tigray, Northern Ethiopia. reproductive health 2014, 11(24).

9. Meskele M, Mekonnen W: Factors affecting women's intention to use long acting and permanent contraceptive methods in Wolaita Zone, Southern Ethiopia. BMC Women's Health 2014, 14(109).

10. Jacobstein R, Stanleya H: Contraceptive implants: providing better choice to meet growing family planning demand. global health: science and prctice 2013, 1(1):1-7.

11. A decade of change in contreptiv use in Ethiopia;indepth analysis of the EDHS 2000-2011. UNFPA 2012.

12. Abajobir AA: Intention to use Long-acting and Permanent Family Planning Methods among Married 15-49 years Women in Debremarkos Town, Northwest Ethiopia. Family Medicine \& Medical Science Research 2014, 3(4).

13. Yalew SA, Zeleke BM, Teferra AS: Demand for long acting contraceptive methods and associated factors among family planning service users, Northwest Ethiopia: a health facility based cross sectional study. BMC Research Notes 2015, 8(29).

14. Rhoades DR A-OKS, Penprase B: Understanding overweight adolescents' beliefs using the theory of planned behaviour. International Journal of Nursing Practice 2011; 17: 562-570 2011(17):562-570.

15. Lee J, A F, Cerreto, Lee J: Theory of Planned Behavior and Teachers' Decisions Regarding Use of Educational Technology. Educational Technology \& Society 2010, 13(1):152-164.

16. Charoenung T, Nimpitakpong P, Chaijinda K, Jedsadayanmata A:development of a questionnaire based on the theory of planned behaior to identify factors affecting pharmacists' intention to consult physicians on drug related problems. 2012.

17. Innan R, Moustaghfir K: predicting employees' behavior:an application of the theory of planned behavior - the case of the moroccan forestry department (HCEFLCD).2012

18. getnet $\mathrm{s}$, abdurehman ma, kemaw $\mathrm{n}$, kansa t, getachew $\mathrm{z}$, hailu $\mathrm{d}$, workneh $\mathrm{y}$ : long acting contraceptive method utilization and associated factors among reproductive age women in arbaminch,town,ethiopia. Greener journal of epydemology and public health 2014(2354-2381). 
19. Agha S: Intentions to use contraceptives in Pakistan:implications for behavior change campaigns. BMC Public Health 2010, 10:450, 10(450):5-13.

20. Meskele1 M, Mekonnen W: Factors affecting women's intention to use long acting and permanent contraceptive methods in Wolaita Zone, Southern Ethiopia:. BMC Women's Health 20142014 , 14(109).

21. Tekelab T, Sufa A, Wirtu D: Factors Affecting Intention to Use Long Acting and Permanent Contraceptive Methods among Married Women of Reproductive Age Groups in Western Ethiopia:. Family Medicine \& Medical Science Research 2014.

22. Carson-DeWitt R: Addressing Unmet Need for Family Planning in Africa. Family Health International 2007.

23. AJZEN I: Constructing a TpB Questionnaire: Conceptual and Methodological Considerations. . 2006. 